\title{
Children in language shift - the syntax of fifth generation, pre-school, Indian South African English speakers
}

\section{Rajend Mesthrie}

To cite this article: Rajend Mesthrie (2003) Children in language shift - the syntax of fifth generation, pre-school, Indian South African English speakers, Southern African Linguistics and Applied Language Studies, 21:3, 119-126, DOI: 10.2989/16073610309486335

To link to this article: http://dx.doi.org/10.2989/16073610309486335

曲 Published online: 12 Nov 2009.

Submit your article to this journal $\pi$

Џlll Article views: 21

Q View related articles 5

Citing articles: 4 View citing articles $\square$ 


\title{
Children in language shift - the syntax of fifth generation, pre-school, Indian South African English speakers
}

\author{
Rajend Mesthrie \\ Linguistics Section, Department of English, University of Cape Town, Private Bag, Rondebosch \\ 7701, South Africa \\ e-mail: raj@humanities.uct.ac.za
}

\begin{abstract}
Language shift, the process by which a second language ousts a community's first language as the everyday vernacular, almost inevitably throws up a vast array of morpho-syntactic and phonetic variety in the new vernacular. This paper seeks to ascertain what choices the first post-shift generation of child learners makes from such an array of competing forms. Data from longitudinal studies undertaken in the early to mid-1990s is presented from Indian South African English, focussing on fifth generation, monolingual, pre-school children in a natural (i.e. non-classroom) setting. The paper shows that while these children do make a selection of the morpho-syntactic variants in the elder's speech, there is no syntactic innovation. On the other hand, a surprisingly large number of former second-language features persist in post-shift speech, probably enhanced by the peculiarities of apartheid society, during which these children acquired their vernacular.
\end{abstract}

\section{Introduction}

Indian South African English (henceforth ISAE) spoken by over three quarters of a million people, chiefly in the province of KwaZulu-Natal, offers the linguist and sociologist an opportunity of examining the dynamics of language shift. A detailed study of the means by which English has become established as the first language of this speech community, ousting in the process 'ancestral' languages is offered in Mesthrie (1992). In that study I emphasised the type of language acquisition involved and the kind of variation that arose in this particular instance of language shift. The present paper is essentially concerned with the selection that child learners make when confronted with such a wide array of syntactic choices. This process of selection is of current interest in the field of language contact, in which there is considerable debate whether children are innovators or not. Bickerton's bioprogramme hypothesis credited children almost entirely with the process of innovation/creation during creolisation. On the other hand situations of creolisation that are open to current observation (Tok Pisin, see Mühlhäusler, 1991; West African Pidgin English, see Faraclas, 1996) suggest that expanded pidgins, to which adults are known to have contributed, are not qualitatively different from L1 creole versions of them. This raises the question whether children are really as innovative as previously believed. Studies of children's language in 'New English' contexts are rare. The one full-length study by Gupta (1994) on English as L1 amongst Singapore children does not commit itself to comparisons with pre-shift adult norms. I will first provide a short introduction to ISAE, then summarise some of the variation found amongst older speakers, and compare it with that of preschool children. The paper will also compare the baby-talk of parents and grandparents with early child language.

ISAE owes its origins to the migration of just over 152000 indentured workers from various parts of north and south India (chiefly presentday Bihar and Uttar Pradesh, and Tamil Nadu and Andhra Pradesh respectively) between 1860 and 1911 as cheap labour for the cane fields of Natal. Smaller numbers of traders chiefly from Gujarat followed from 1875 onwards. Less than optimal conditions of education in the early phases and the subsequent policy of apartheid (1948-1992) kept ISAE as a social dialect relatively unaffected by the form of English spoken by Whites in the province of Natal. A large number of Indian languages are 
still spoken in the country, though they have been greatly on the decline since the late 1950 s, with steadily decreasing numbers of first- and even second-language learners.

In the late 1950s and early 1960s English started to become the first language of a majority of Indian schoolchildren; it derived from and co-existed with - the L2 English of a large number of adults. The period of shift can be considered gradual or rapid, depending on one's determining criteria. As 1960 was exactly one hundred years since the first immigration the period of shift might seem a gradual one; but as 1960 was also less than fifty years after the last shipload of 1911, the period is perhaps not all that gradual.

\section{Language shift}

This paper will not be focussing on the role of children in the early stages of language shift in ISAE, because those stages are no longer amenable to observation - having taken place essentially in the late 1950s and early 1960s. Although most parents at that time spoke to pre-school children in the ancestral language, once they began formal education, children started to bring home the language of the school and playground - English. Some parents themselves were influenced by their children to start using (or re-using, if they had been to school) some English in the home. It was not uncommon for the second and third child in a family to arrive at school with a fair grasp of the new language. In some cases, especially in large families, the impact of English was so great and rapid that the youngest child could arrive at school with a spoken command of English only, in stark contrast to the older children in the family. In some rural homes parents (especially mothers) learnt English from the youngest children, rather than vice versa. This process, which I call 'a closed cycle of reinforcement' in language shift, continues till today, though it is now manifest in the interactions between grandparents (especially grandmothers) and grandchildren. That is, those grandparents with little or no schooling who spoke an Indian language to their children a generation ago are now forced to learn English in order to be intelligible to monolingual grandchildren. (In some homes grandchildren are lucky enough to receive input from grandparents in an ancestral language, but this is now rare.) This closed cycle of reinforcement is remarkable for its potential two-way influence: the grandparent learns from, and with, the grandchild, and in turn reinforces the latter's child-language. As one of my interviewees discussing his wife's knowledge of English put it, "Now with her purposes too, her grandchildren all growing y'see, now she must communicate with them in the language they understand [English]. So she goes along with that language. They teach the grandparents how to speak the language." (emphasis mine)

A similar process is apparent in the quote following from an elderly female teacher of Urdu in Durban. When asked by Aziz (1988: 60 ), who was investigating the current status of Urdu in Natal, why she used English as a medium of instruction, she replied (in Urdu), "No pupil would open his mouth to speak to me in Urdu so I preferred to speak to him in English. He would have no embarrassment and I also would be improving my English. The parents do the same." (emphasis added by Aziz)

\section{Baby-talk and child language}

ISAE is characterised by a great deal of styleshifting. Speakers whose repertoire is best described as mesolectal or acrolectal often drop back to a lower lect when addressing children. (On a broader ethnographic level I would venture that children within this community are treated as children for a much longer time than in other communities.) In one of my ISAE interviews of 1986-1988 an upper working-class male gave a relaxed, clearly mesolectal performance. In speaking to his six-year-old daughter, he dropped back significantly using the following basilectal expressions: Tell what's the name; Tell, tell how you play colour-cards. Later he had to restrain the exuberant child with Wait, wait, daddy talking. Incidents like this were by no means isolated: whenever children made an appearance, adult interviewees downshifted to a basilect-like variety when addressing them. In these examples 'downshifting' involves the use of tell and talk for 'say', verb repetition and auxiliary deletion before present progressives.

In establishing the extent of this practice and the links between the basilect, child language and baby-talk I was fortunate enough to be able to tape two sisters (aged 60 and 62 ) in 1991 talking to the 3-year-old grandson of one of them; and subsequently, the same two sis- 
ters in an all-adult conversation. On both occasions I left a tape-recorder running, with the bona fide instruction that the sisters speak Bhojpuri for the benefit of my research and for posterity. This, of course ensured that they totally ignored my request and used English most of the time! (Whereas they usually speak Bhojpuri to each other, the presence of younger people often leads to English dominance.) In Table 1 I present a comparison via informal statistics of the most salient features of the more talkative sister (Granny CC) speaking to adults and to the grandchild.

Since most of the constructions in Table 1 are well-known in the sociolinguistic literature, they are not exemplified here. The only one that is not well known is the absence of be before $V$ +- -ing, as in sentence (1):

(1) Naani telling, 'Put the stove off' (= Granny says, 'Put the stove off'):

Whereas most of the above basilectal features are characterised in a negative way (the absence of features of standard English), we can also list the following 'positive' basilectal features found in the speech addressed to the grandchild:

a. Kinship terms from Indic languages following the proper name: 6/6 (see further 4.2(b))

b. Quasi-postpositions: These were not prominent in speech addressed to the grandchildren, the two examples involved side as the equivalent of 'to, near': go kitchen-side 'go to the kitchen' - see 4.2(c) below. These were outnumbered by the use of prepositions. A related construction used time as a clausefinal equivalent of 'when':

(2) Going-home-time we'll put it on (= 'We'll put it on just before we leave for home').

c. Only and too as focus markers: There were one each of these:

(3) Go see, the donkey came 'way too (= 'Take a look; the donkey has arrived' no other animal mentioned at this stage).

(4) Naani only was scolding her ( = 'Granny was really scolding her').

d. Never with unmarked verb as simple past or perfective negative:

(5) They never hear (= 'They haven't heard / They didn't hear').

e. Bimorphemic forms: what-thing 'what'; thisside 'here'; that-side 'there'.

It is therefore quite clear that there is considerable downshifting in baby-talk, involving the increase in frequency of basilectal constructions. The grandmother used only two items in baby-talk that did not occur in her adult speech - unmarked verb forms for the past (see d) above) and it as a kind of verb suffix:

(6) Grandchild: New car got-it.

Grandmother: Got-it what?

Grandchild: New car.

Grandmother: Where's the new car?

Grandchild: Got-it inside the garage.

I suggest that there is a larger degree of overlap between the basilect and child-language than between adult speech in other English dialects and child language. It should not be anticipated that the ISAE child will use

Table 1: A comparison of the grammatical forms used by Granny CC to grandchild, versus Granny CC to other adults

\begin{tabular}{lcc}
\hline & To grandchild & To adult \\
\hline $3^{\text {rd }}$ singular present verb ending $-s^{\text {a }}$ & $0 / 5$ & $4 / 12$ \\
Unmarked verb forms for past & $3 / 12$ & $0 / 20$ \\
Absence of auxiliary-inversion & $2 / 2$ & $5 / 5^{b}$ \\
Absence of do-support & $2 / 2$ & $3 / 3^{c}$ \\
Copula absenced & $14 / 18^{\text {c }}$ & $7 / 25$ \\
Absence of $3^{\text {rd }}$ singular be before verb + -ing & $3 / 3$ & $1 / 10$ \\
\hline
\end{tabular}

a On the other hand, the use of $-s$ plural for nouns was close to mandatory (16/18 with the grandchild) and of the possessive $-s$ ending (4/4 with the grandchild).

b This included including four wh-questions

c This included one wh-question

d Here I exclude phonological absence of $2^{\text {nd }}$ person 're

e This included two with zero subjects 
only basilect-like, child-language forms and for long, since s/he is also exposed to adult-toadult conversations and the speech of older children. The speech of the grandchild of this section has not been analysed for the simple reason that there was very little of it - the grandmothers tended to dominate. In the next section I will analyse the speech of three other pre-school children studied longitudinally over a two-year period.

\section{Syntactic choices of three children}

In this section I examine the extent to which a former L2 approximates the superstrate language once it becomes an L1. In a society that was just beginning to put aside the legacy of apartheid in the early to mid-1990s, the English of Whites was still not generally available to pre-school ISAE speakers (except on television). Consequently, a more realistic question is whether the former L2 moves away from the basilect towards the ISAE acrolect. My analysis is based on taped interactions with three children in Natal, spaced over three roughly sixmonth intervals between 1991 and $1992 .^{1}$ On no occasion was there a one-on-one interview - rather children were taped while at play with their siblings or as part of a family group within their homes. Each session lasted between forty-five and seventy-five minutes. The database thus contains stretches of speech samples of elder siblings, but as these were not pre-school children, their speech is not directly pertinent to this study. Essential details concerning the three children are as follows (pseudonyms are used in this paper) ${ }^{2}$ :

a. Johnny: Taped at ages $3 ; 11,4 ; 11$ and 5;4. Rural working-class background; Christian male; understands some of, but is unable to speak, the family ancestral language, Tamil; youngest child with two sisters; living with lower-mesolectal parents (with an average of seven years schooling) and a prebasilectal grandmother; also grew up with a basilectal grandfather (now deceased).

b. Roshan: Taped at ages 3;6, 4;2 and 4;10. Rural middle-class background; Hindu male; cannot understand the ancestral language, Bhojpuri; youngest child, with a brother; living with mid-mesolectal parents (with an average of ten years of schooling) and mid-mesolectal grandparents.

c. Tarika: Taped at ages $2 ; 11,3 ; 11$ and $4 ; 4$.
Urban middle-class background; Hindu female; cannot understand the ancestral language, Gujarati; youngest child, until last interview, now with an elder sister and younger brother; living with acrolectal parents and upper-mesolectal grandmother.

Since my aim is to compare child learnersystems with adult norms, it is important to separate genuinely transient child-language forms from dialect features. With the backing of the 150 interviews of adult and teenage speech (Mesthrie, 1992) this can be easily done. The following are some examples that can be confidently attributed to child-learner errors, rather than ISAE dialect:

(7) I'm don' wanna sing.

(8) I writed my name down.

(9) The blue one is the most biggest.

(10)I drinks.

On the other hand, the following are not transient forms, since they are part of some lect or other within ISAE and will not be corrected by elders or peers in casual speech:

(11) My mother saying (= 'My mother says')

(12) He never eat (= 'He hasn't eaten')

(13) Mary-them-an'-all's school (= 'The school of Mary and associates' $)^{3}$

(14) I was frightened of the dog (= 'I was afraid of the dog')

(15) But my mummy told, "mustn't chase it by the dog" (= "But my mother told me not to chase it towards the dog')

(16) Connie look-afters Kapil (= 'Connie looks after Kapil')

\subsection{Child language and the basilect}

I argue in Mesthrie (1992) that the basilect is a focussed, creole-like variety, which is overtly denigrated when used in public situations, but which carries a great deal of covert prestige. Given that there are significant overlaps between the basilect and baby-talk (section 2) a comparison between this lect and child language would appear to be a promising activity. A few basilectal constructions did not appear on the tape, probably because they are not yet in the children's stylistic range (e.g. rhetorical whquestions and reduplication). ${ }^{4}$ In this section we will concentrate on OV constructions and auxiliary shift.

\subsection{OV relics in child language}

The issue that interests me most (see Mesthrie, 
1987 ) is the extent to which constructions reminiscent of an OV typology (of all the substrate languages, which have the order Subject-Object-Verb as the norm) linger on in the English of the fourth and fifth generation. In this vein I will focus on relative clauses, kinship syntax and quasi-postpositions.

\section{(a) Relative clauses}

Of a whole array of relative clauses in adult ISAE, approximately $4.5 \%$ follow patterns associated with an OV typology (Mesthrie, 1992: 72-81). These include correlatives, prenominal-external relatives and a prenominal participial strategy (see sentences 17-19):

(17) Which-one I put in the jar, that-one is good. (= 'The ones (i.e. pickles) which I put in the jar are the best') - correlative, see Mesthrie (1992: 73-75).

(18) That's all we had trouble. (= 'That's all the trouble we had') - Prenominal external relative, see Mesthrie (1992: 74-76).

(19) You can't beat Vijay's planted tomato. (= 'You won't find better tomatoes than those which Vijay planted') - Prenominal participial relative, see Mesthrie (1992: 76).

There is, in addition, a mixed type showing the restructuring of an OV relative clause into an 'almost-postnominal' type (see which-one relatives below).

Depending on our analysis, Johnny may be said to use nothing but OV or OV-derived relative clauses. One of the four relative clauses he used (at age 3;11) qualifies as a Dravidian pronominal-external type:

(20) $Q$ : What medicine you take?

A: All [doctor-gave-me] medicine I drinks (= 'I drink all the medicine that the doctor gave me')

Like its Tamil counterpart (see Asher, 1985: 25-30), the relative clause here is not marked by a pronoun and precedes the head noun, medicine. It is also not easy to say (as in Tamil usage) whether the head noun belongs to the subordinate or the main clause.

The other three relative clauses that Johnny used also have their basis in basilectal ISAE the use of a mixed relative, which follows the head noun, but has the relative particle preceding an anaphoric representative of the head noun:

(21) Q: The big dog...?
A: Yah, not very big - the small dog which one was growing big.

If we view which one as a simple equivalent of which, then this is a postnominal relative clause, remarkable only for the special form of the relative pronoun which also occurs in the basilect. However, it seems that Johnny intends the meaning 'the one which was growing big' in which case we are dealing with a relative pronoun which preceding its head one. Another example of the same construction (and accompanying analytic dilemma) is given in (22):

(22) $Q$ : Which granny is this?

$A$ : My other granny - which one I went holiday - she don't eat paaku. (= 'My other granny - the one whose house I went on holiday to - doesn't eat betel nut').

On the other hand, neither Roshan nor Tarika show any preference for OV-like relative clauses. Of the four relative clauses used by Roshan, two (at stage I) involved a 'chunk' that dog called Spike, from a television programme. At stage III he used two relative clauses probably more typical of children his age - involving a pronoun strategy (cf. Romaine, 1988: 242).

(23) $Q$ : Now tell me what you saw in the circus.

$A$ : One man he was holding a knife in his mouth. (= 'A man who was holding a knife in his mouth').

It cannot be decided conclusively whether we are dealing with a genuinely transient, universal child-language form or a form that is influenced by the input (or both). The pronoun strategy is the most common strategy of the basilect (and the second most common strategy in ISAE as a whole - at $18 \%$ frequency, see Mesthrie, 1992: 76-81).

Tarika seems to have short-circuited the pronominal strategy for relative clauses, apart from genitives (though this may simply be a problem of gathering data at discrete intervals). Two of the three relative clauses she produced on tape involved standard use of that, as in (24), or $\varnothing$ (i.e. absence of that as in (25):

(24) I was wearing the dress that mummy bought.

(25) That's the only game we play.

However, in one sequence involving a position low down on the Keenan-Comrie hierarchy (the genitive) (see Keenan \& Comrie, 1977) she made recourse to a pronoun strategy: 
(26) Interviewer (sings): One day I called her Misha, one day I called her Tarika; one day I called her Reshma, and threw her down the stairs.

Tarika (interrupts): I got a friend her name

is Reshma (with stress on I, not her).

As with other instances of the pronoun strategy (in child language as well as adult basilect) it is the intonation and lack of pause between clauses that suggests that we are dealing with a single sentence unified by a relative clause. (Hence no comma is used in the transcription.)

The data for relative clauses suggests that basilectal patterns are not being entirely discarded, but that middle-class children have acrolectal norms.

\section{(b) Kinship syntax}

OV languages tend to prefer the order 'Proper Name - Title', hence Japanese Tanaka-san 'Mr Tanaka'. This order occurs in Indic and Dravidian languages as well. These kinship terms have survived the process of language shift very well: dozens of terms may be heard in the English of children who do not have a spoken (and often, a receptive) command of an Indian language. Such terms coexist with the standard English forms, and may show some functional specialisation. For example, uncle is usually used for a distant relative or as a term of respect for any elderly male. For close kin, terms like maama 'maternal uncle', kaaka 'paternal uncle', mousa 'mother's sister's husband', phuppa 'father's sister's husband' may be used (examples are from South African Bhojpuri - equivalents exist from the other substrate languages as well). When such terms are used they follow the syntax of the Indian languages. Thus terms like the following occurred in the child language corpus: Michelle-akka 'sister Michelle' (from Tamil); Sunil-fua 'uncle Sunil' (from Gujarati for 'father's sister's husband'); Shobha-khaki 'aunt Shobha' (from Bhojpuri for 'father's brother's wife').

More significantly, the pattern may extend to English kinship terms as well. Johnny used only the pattern calqued (by elders) on Indic/Dravidian usage: thus George-uncle; Vijay-uncle, etc. $(\mathrm{n}=5)$. Roshan used both types: thus Uncle Abdul, but Christmas-father ( $n=2$ for the latter). Tarika used only the
English pattern: Uncle Vijay; Father Christmas $(n=3)$.

\section{(c) Quasi-postpositions}

In adult basilect the quasi-postpositions time, side, part occur as frequent equivalents of 'in', 'near', 'toward' and 'during' respectively. Of these only time occurred in the child corpus, though I would not be surprised to hear the others on other occasions. Although Johnny uses mostly standard English prepositions, he favours expressions like dark-time and nighttime for 'in the dark' and 'at night'. He used dark-time four times as against one occurrence of in the dark. For the same phrase ('fear of darkness', rather than 'danger of death', seems to be an appropriate motif for children's speech) Roshan used in the night $(\mathrm{n}=1)$, but not night-time; Tarika used in the night once, and intermediate (mesolect-like) forms like it's night-time on (= 'it's on in the night') and from night-time (= 'from the night onwards').

\subsection{Other constructions}

In this section I will examine the use that children make of two typically basilectal constructions.

\section{(a) Auxiliary-shift}

Common in most varieties of informal English is the use of statement word order, with rising sentence intonation for non-echo questions, where the syntax of formal standard-English requires inversion of an auxiliary verb and subject NP. An example is You can do it? compared to formal standard-English Can you do it? Non-application of the rule occurs in most other varieties of South African English, where it is limited to interrogatives. ISAE generalises the rule to include wh-questions. That ISAE makes particularly high use of non-inversion in questions can be gauged from Table 2 (Mesthrie, 1992: 47) and

Table 2: Absence of auxiliary inversion among twenty-four adult speakers in wh- and yes-no questions (from Mesthrie, 1992: 47)

\begin{tabular}{lccc}
\hline & Wh- & Yes-no & Total \\
\hline Basilect & $12 / 17$ & $3 / 5$ & $15 / 22$ \\
Mesolect & $3 / 7$ & $0 / 1$ & $3 / 8$ \\
Acrolect & $0 / 9$ & $1 / 4$ & $1 / 13$ \\
Total & $15 / 33$ & $4 / 10$ & $19 / 43$ \\
\hline
\end{tabular}


from occasional remarks by people exposed to informal use of the dialect for the first time. (In formal speech inversion is the norm.)

The proportions of non-inversion to inversion were much higher in child-language, though children already have inversion as a stylistic option, as (30) and (31) show. Some examples from child language follow:

(27) I must go an' pull an' show you? (= 'Must I pull it out and show you?')

(28) Y'all never do it? (= 'Didn't you (pl) do it?')

(29) What I must say? (= 'What must I say?')

(30) Mummy, can you cut my egg? (rare, directive question)

(31) What's brinjal?

The statistics are given in Table 3. Note that the two instances of inversion under wh- are actually instances of attraction of the reduced copula 's to wh- words (what's in both instances).

A further comparison with American childlanguage norms is possible, based on Ingram and Tyack's analysis of 21 children from ages 2;4 to 3;2+, summarised in Ingram (1989: 458). Their figures, based on child narratives, show a high rate of inversion in both auxiliary and whquestions at an early age (Table 4).

The ISAE-speaking children would fall into groups $B(2 ; 11)$ and $D, E-F(3 ; 2+)$. The index for $B$ in this case is 0.0 for both yes-no $(n=4)$ and wh- questions $(\mathrm{n}=3)$. For $\mathrm{D}, \mathrm{E}-\mathrm{F}$ it is also low in comparison: 33.3 for both types of questions ( $n=3$ and 4 respectively).

\section{(b) Do-support}

For many adult ISAE speakers interrogative questions lacking an auxiliary have a parallel syntax to those which have an auxiliary; i.e. they do not use do in this construction. In most styles ISAE has You go there?, You saw me? where other dialects require Do you go there?, Did you see me? Again, anecdotal evidence suggests that speakers of other dialects of South African English coming into contact with informal ISAE for the first time notice the frequent absence of do-support. (This rule, of course, goes hand-inhand with the (non-) inversion rule. Note that do-support always occurs in negative statements and negative questions, except in the pre-basilect.) The statistics for 24 adult speakers are given in Table 5 .

Table 6 shows that the children do not yet show any use of do-support (apart from nega-
Table 3: Absence of auxiliary inversion in wh- and yes-no questions in child language

\begin{tabular}{lccc}
\hline & Wh- & Yes-no & Total \\
\hline Johnny & $2 / 3$ & $1 / 1$ & $3 / 4$ \\
Roshan & $0 / 1$ & $1 / 2$ & $1 / 3$ \\
Tarika & $5 / 5$ & $4 / 4$ & $9 / 9$ \\
Total & $7 / 9$ & $6 / 7$ & $13 / 16$ \\
\hline
\end{tabular}

Table 4: Inversion rates for US children

\begin{tabular}{lccc}
\hline Period & $\begin{array}{c}\text { Number of } \\
\text { subjects }\end{array}$ & $\begin{array}{c}\text { Yes-no } \\
\text { questions }\end{array}$ & Wh-questions \\
\hline A $\quad(2 ; 4)$ & 7 & 0.55 & 0.77 \\
B $\quad(2 ; 11)$ & 3 & 0.81 & 0.91 \\
C $\quad(3 ; 2)$ & 5 & 0.91 & 0.96 \\
D $\quad(3 ; 2+)$ & 4 & 0.98 & 0.95 \\
E-F $(3 ; 2+)$ & 2 & 0.97 & 0.95 \\
\hline
\end{tabular}

Table 5: Non-use of do-support in wh- and yes-no questions by twenty-four adult speakers (from Mesthrie, 1992: 48)

\begin{tabular}{lccc}
\hline & Wh- & Yes-no & Total \\
\hline Basilect & $4 / 4$ & $11 / 11$ & $15 / 15$ \\
Mesolect & $3 / 3$ & $2 / 2$ & $5 / 5$ \\
Acrolect & $0 / 2$ & $1 / 4$ & $1 / 6$ \\
Total & $7 / 9$ & $14 / 17$ & $21 / 26$ \\
\hline
\end{tabular}

Table 6: Non-use of do-support in wh- and yes-no questions in child language

\begin{tabular}{lccc}
\hline & Wh- & Yes-no & Total \\
\hline Johnny & $3 / 3$ & $1 / 1$ & $4 / 4$ \\
Roshan & $2 / 2$ & $1 / 1$ & $3 / 3$ \\
Tarika & $7 / 7$ & $1 / 1$ & $8 / 8$ \\
Total & $12 / 12$ & $3 / 3$ & $15 / 15$ \\
\hline
\end{tabular}

tive statements and questions, where they are mandatory).

In contradistinction to other basilectal features, lack of inversion and do-support seem to have stabilised as part of fourth- and fifth-generation vernacular speech, irrespective of the social-class background of the children.

\section{Conclusion}

Syntactic variation in ISAE begins at an early age, with children of working-class background retaining some of the basilectal norms of adult 
speech better than other children. The ISAE pre-school children do not appear to be syntactic innovators. At this late stage of language shift their main role is in the selection and focussing of the very wide range of variants available to them in adult speech (with some differences according to social class). Overall, children are less basilectal than their elders, in the sense that their rates of deletion of elements like auxiliaries and the use of OV constructions is much lower by stage III (average age $4 ; 10)$.

Acknowledgements - I would like to thank the following for brief but helpful comments on an early draft of this paper at the Sociolinguistics Symposium, University of Reading, 1992: Gillian Sankoff, Jean Aitchison, Julia Khan, Eddie Williams, Paul Kerswill, Conrad Ozog and Diane Eaden. Thanks are also due to Catherine Snow

\section{Notes}

1 There was one exception of a twelve-month interval for one of the children.

\section{References}

Asher R. 1985. Tamil. London: Croom Helm.

Aziz AK. 1988. An Investigation into the Factors Governing the Persistence of Urdu as a Minority Language in South Africa. MA Thesis, University of South Africa, Pretoria.

Faraclas N. 1996. Nigerian Pidgin. London: Routledge.

Gupta AF. 1994. The Step-Tongue Children's English in Singapore. Clevedon, UK: Multilingual Matters.

Ingram D. 1989. First-language Acquisition Method, Description and Explanation. Cambridge: Cambridge University Press.

Keenan E \& Comrie B. 1977. Noun-phrase accessibility and universal grammar. Linguistic Inquiry 8: 63-99.
2 I had started off with a fourth child from an urban, working-class background, but was discouraged from conducting follow-up studies by his mother, who expressed fears about child abuse in the neighbourhood. Although unhappy with the absence of a child from such a background, I am nevertheless satisfied with the data base of three children from different social networks studied over several years.

3 This utterance is only unusual insofar as it has a double associative plural marker. In adult speech either plural form is acceptable; double forms are rare.

4 The children do use one type of reduplication which is rare in adult ISAE - forms pertaining to children's games, e.g. house-house game, mummy-mummy, lie-lie ('a game of make-believe'). None of the children, however, shows any other type of reduplication frequent in adult ISAE.

Mesthrie R. 1987. From OV to VO in language shift - Indian South African English and its OV substrates. English World-Wide 8: 263-76.

Mesthrie R. 1992. English in Language Shift The History, Structure and Sociolinguistics of Indian South African English. Cambridge: Cambridge University Press.

Mühlhäusler P. 1991. Overview of pidgin and Creole languages of Australia. In: Romaine $S$ (ed) Language in Australia. Cambridge: Cambridge University Press. pp. 159-73.

Romaine S. 1988. Pidgin and Creole Languages. London: Longman. 